\title{
Respiratory System Findings Derived Flag
}

National Cancer Institute

\section{Source}

National Cancer Institute. Respiratory System Findings Derived Flag. NCI Thesaurus.

Code C124037.

An indication or description that respiratory system data is a derived value. 